Research Article

\title{
Some Ostrowski Type Inequalities for Harmonically $(s, m)$-Convex Functions in Second Sense
}

\author{
Imran Abbas Baloch ${ }^{1}$ and İmdat İşcan ${ }^{2}$ \\ ${ }^{1}$ Abdus Salam School of Mathematical Sciences, GC University, Lahore 54600, Pakistan \\ ${ }^{2}$ Department of Mathematics, Faculty of Arts and Sciences, Giresun University, 28200 Giresun, Turkey
}

Correspondence should be addressed to Imran Abbas Baloch; iabbasbaloch@gmail.com

Received 8 July 2015; Accepted 10 September 2015

Academic Editor: Rodica D. Costin

Copyright @ 2015 I. A. Baloch and İ. İşcan. This is an open access article distributed under the Creative Commons Attribution License, which permits unrestricted use, distribution, and reproduction in any medium, provided the original work is properly cited.

The authors introduce the concept of harmonically $(s, m)$-convex functions in second sense and establish some Ostrowski type inequalities of these classes of functions.

\section{Introduction}

Let $f: I \subseteq \mathbb{R} \rightarrow \mathbb{R}$ be a mapping differentiable in $I^{\circ}$ and $a, b \in I$ with $a<b$. If $\left|f^{\prime}(x)\right| \leq M$, for all $x \in[a, b]$, then the following inequality holds:

$$
\begin{aligned}
& \left|f(x)-\frac{1}{b-a} \int_{a}^{b} f(t) d t\right| \\
& \quad \leq M(b-a)\left[\frac{1}{4}+\frac{(x-(a+b) / 2)^{2}}{(b-a)^{2}}\right]
\end{aligned}
$$

for $x \in[a, b]$. This inequality is known in the literature as the Ostrowski inequality [1], which gives an upper bound for the approximation of the integral average $(1 /(b-a)) \int_{a}^{b} f(t) d t$ by the value $f(x)$ at the point $x \in[a, b]$. For some results which generalize, improve, and extend inequality (1), we refer the reader to recent papers (see $[2,3])$ and monograph of $[4]$.

In [5], İşcan introduced class of harmonically convex functions. This class of functions is defined as follows.

Definition 1. Let $I \subset \mathbb{R} /\{0\}$ be a real interval. A function $f$ : $I \rightarrow \mathbb{R}$ is said to be harmonically convex, if

$$
f\left(\frac{x y}{t x+(1-t) y}\right) \leq t f(y)+(1-t) f(x)
$$

for all $x, y \in I$ and $t \in[0,1]$. If inequality in (2) is reversed, then $f$ is said to be harmonically concave.
In [6], İscan introduced the concept of harmonically $s$ convex function in second sense and established a variant of Ostrowski type inequalities which hold for these classes of functions as follows.

Definition 2. A function $f: I \subset \mathbb{R} /\{0\} \rightarrow \mathbb{R}$ is said to be harmonically $s$-convex in second sense, if

$$
f\left(\frac{x y}{t x+(1-t) y}\right) \leq t^{s} f(y)+(1-t)^{s} f(x)
$$

for all $x, y \in I$ and $t \in[0,1]$ for some fixed $s \in(0,1]$. If inequality in (3) is reversed, then $f$ is said to be harmonically $s$-concave.

Remark 3. Note that, for $s=1$, harmonically $s$-convexity reduces to ordinary harmonic convexity.

Theorem 4. Let $f: I \subset(0, \infty) \rightarrow \mathbb{R}$ be a differentiable function on $I^{\circ}, a, b \in I^{\circ}$ with $a<b$ and $f^{\prime} \in L[a, b]$. If $\left|f^{\prime}\right|^{q}$ is harmonically s-convex on $[a, b]$ for $q \geq 1$, then, for all $x \in$ $[a, b]$, we have

$$
\begin{aligned}
& \left|f(x)-\frac{a b}{b-a} \int_{a}^{b} \frac{f(u)}{u^{2}} d u\right| \leq \frac{a b}{b-a}\left\{(x-a)^{2}\right. \\
& \cdot\left(\lambda_{1}(a, x, s, q, q)\left|f^{\prime}(x)\right|^{q}\right. \\
& \left.+\lambda_{2}(a, x, s, q, q)\left|f^{\prime}(a)\right|^{q}\right)^{1 / q}+(b-x)^{2}
\end{aligned}
$$




$$
\begin{aligned}
& \cdot\left(\lambda_{3}(b, x, s, q, q)\left|f^{\prime}(x)\right|^{q}\right. \\
& \left.\left.+\lambda_{4}(b, x, s, q, q)\left|f^{\prime}(b)\right|^{q}\right)^{1 / q}\right\},
\end{aligned}
$$

where

$$
\begin{aligned}
\lambda_{1}(a, x, s, \vartheta, \rho) & \\
= & \frac{\beta(\rho+s+1,1)}{x^{2 \vartheta}} \\
& \cdot{ }_{2} F_{1}\left(2 \vartheta, \rho+s+1 ; \rho+s+2,1-\frac{a}{x}\right), \\
\lambda_{2}(a, x, s, \vartheta, \rho) & \\
= & \frac{\beta(\rho+1,1)}{x^{2 \vartheta}} \cdot{ }_{2} F_{1}\left(2 \vartheta, \rho+1 ; \rho+s+2,1-\frac{a}{x}\right), \\
\lambda_{3}(b, x, s, \vartheta, \rho) & \frac{\beta(1, \rho+s+1)}{b^{2 \vartheta}} \cdot{ }_{2} F_{1}\left(2 \vartheta, 1 ; \rho+s+2,1-\frac{x}{b}\right), \\
\lambda_{4}(b, x, s, \vartheta, \rho) & \frac{\beta(s+1, \rho+1)}{b^{2 \vartheta}} \\
= & { }_{2} F_{1}\left(2 \vartheta, s+1 ; \rho+s+2,1-\frac{x}{b}\right) .
\end{aligned}
$$

$\beta$ is Euler Beta function defined by

$$
\beta(x, y)=\frac{\Gamma(x) \Gamma(y)}{\Gamma(x+y)}=\int_{0}^{1} t^{x-1}(1-t)^{y-1} d t
$$

$$
x, y>0
$$

and ${ }_{2} F_{1}$ is hypergeometric function (see [4]) defined by

$$
\begin{aligned}
& { }_{2} F_{1}(a, b ; c, z) \\
& =\frac{1}{\beta(b, c-b)} \int_{0}^{1} t^{b-1}(1-t)^{c-b-1}(1-z t)^{-a} d t, \\
& c>b>0,|z|<1 .
\end{aligned}
$$

$$
\begin{aligned}
& \left|f(x)-\frac{a b}{b-a} \int_{a}^{b} \frac{f(u)}{u^{2}} d u\right| \leq \frac{a b}{b-a} M\left\{(x-a)^{2}\right. \\
& \cdot\left(\lambda_{1}(a, x, s, q, q)+\lambda_{2}(a, x, s, q, q)\right)^{1 / q}+(b-x)^{2} \\
& \left.\cdot\left(\lambda_{3}(b, x, s, q, q)+\lambda_{4}(b, x, s, q, q)\right)^{1 / q}\right\}
\end{aligned}
$$$$
\text { holds. }
$$

Theorem 6. Let $f: I \subset(0, \infty) \rightarrow \mathbb{R}$ be a differentiable function on $I^{\circ}, a, b \in I^{\circ}$ with $a<b$ and $f^{\prime} \in L[a, b]$. If $\left|f^{\prime}\right|^{q}$ is harmonically s-convex on $[a, b]$ for $q \geq 1$, then, for all $x \in$ $[a, b]$, one has

$$
\begin{aligned}
& \left|f(x)-\frac{a b}{b-a} \int_{a}^{b} \frac{f(u)}{u^{2}} d u\right| \leq \frac{a b}{b-a}\left(\frac{1}{2}\right)^{1-1 / q}\{(x \\
& \quad-a)^{2}\left(\lambda_{1}(a, x, s, q, 1)\left|f^{\prime}(x)\right|^{q}\right. \\
& \left.\quad+\lambda_{2}(a, x, s, q, 1)\left|f^{\prime}(a)\right|^{q}\right)^{1 / q}+(b-x)^{2} \\
& +\left(\lambda_{3}(b, x, s, q, 1)\left|f^{\prime}(x)\right|^{q}\right. \\
& \left.\left.+\lambda_{4}(b, x, s, q, 1)\left|f^{\prime}(b)\right|^{q}\right)^{1 / q}\right\},
\end{aligned}
$$

where $\lambda_{1}, \lambda_{2}, \lambda_{3}$, and $\lambda_{4}$ are defined as in Theorem 4.

Corollary 7. In Theorem 6, additionally, if $\left|f^{\prime}(x)\right| \leq M, x \in$ $[a, b]$, then the inequality

$$
\begin{gathered}
\left|f(x)-\frac{a b}{b-a} \int_{a}^{b} \frac{f(u)}{u^{2}} d u\right| \leq \frac{a b}{b-a} M\left(\frac{1}{2}\right)^{1-1 / q} \\
\cdot\left\{(x-a)^{2}\left(\lambda_{1}(a, x, s, q, 1)+\lambda_{2}(a, x, s, q, 1)\right)^{1 / q}\right. \\
\left.+(b-x)^{2}\left(\lambda_{3}(b, x, s, q, 1)+\lambda_{4}(b, x, s, q, 1)\right)^{1 / q}\right\}
\end{gathered}
$$

holds.

Theorem 8. Let $f: I \subset(0, \infty) \rightarrow \mathbb{R}$ be a differentiable function on $I^{\circ}, a, b \in I^{\circ}$ with $a<b$ and $f^{\prime} \in L[a, b]$. If $\left|f^{\prime}\right|^{q}$ is harmonically s-convex on $[a, b]$ for $q \geq 1$, then, for all $x \in$ $[a, b]$, one has

$$
\begin{aligned}
& \left|f(x)-\frac{a b}{b-a} \int_{a}^{b} \frac{f(u)}{u^{2}} d u\right| \leq \frac{a b}{b-a}\left\{\lambda_{5}^{1-1 / q}(a, x)(x\right. \\
& -a)^{2}\left(\lambda_{1}(a, x, s, 1,1)\left|f^{\prime}(x)\right|^{q}\right. \\
& \left.\quad+\lambda_{2}(a, x, s, 1,1)\left|f^{\prime}(a)\right|^{q}\right)^{1 / q}+\lambda_{5}^{1-1 / q}(b, x)(b \\
& \quad-x)^{2}\left(\lambda_{3}(b, x, s, 1,1)\left|f^{\prime}(x)\right|^{q}\right. \\
& \left.\left.+\lambda_{4}(b, x, s, 1,1)\left|f^{\prime}(b)\right|^{q}\right)^{1 / q}\right\},
\end{aligned}
$$

where

$$
\lambda_{5}(\theta, x)=\frac{1}{x-\theta}\left\{\frac{1}{\theta}-\frac{\ln x-\ln \theta}{x-\theta}\right\}
$$

and $\lambda_{1}, \lambda_{2}, \lambda_{3}$, and $\lambda_{4}$ are defined as in Theorem 4 . 
Corollary 9. In Theorem 8, additionally, if $\left|f^{\prime}(x)\right| \leq M, x \in$ $[a, b]$, then the inequality

$$
\begin{aligned}
& \left|f(x)-\frac{a b}{b-a} \int_{a}^{b} \frac{f(u)}{u^{2}} d u\right| \leq \frac{a b}{b-a} M\left\{\lambda_{5}^{1-1 / q}(a, x)\right. \\
& \cdot(x-a)^{2}\left(\lambda_{1}(a, x, s, 1,1)+\lambda_{2}(a, x, s, 1,1)\right)^{1 / q} \\
& +\lambda_{5}^{1-1 / q}(b, x)(b-x)^{2} \\
& \left.\cdot\left(\lambda_{3}(b, x, s, 1,1)+\lambda_{4}(b, x, s, 1,1)\right)^{1 / q}\right\}
\end{aligned}
$$

holds.

Theorem 10. Let $f: I \subset(0, \infty) \rightarrow \mathbb{R}$ be a differentiable function on $I^{\circ}, a, b \in I^{\circ}$ with $a<b$ and $f^{\prime} \in L[a, b]$. If $\left|f^{\prime}\right|^{q}$ is harmonically s-convex on $[a, b]$ for $q>1,1 / p+1 / q=1$, then, for all $x \in[a, b]$, one has

$$
\begin{aligned}
& \left|f(x)-\frac{a b}{b-a} \int_{a}^{b} \frac{f(u)}{u^{2}} d u\right| \leq \frac{a b}{b-a}\left(\frac{1}{1+p}\right)^{1 / p}\{(x \\
& \quad-a)^{2}\left(\lambda_{1}(a, x, s, q, 0)\left|f^{\prime}(x)\right|^{q}\right. \\
& \left.\quad+\lambda_{2}(a, x, s, q, 0)\left|f^{\prime}(a)\right|^{q}\right)^{1 / q}+(b-x)^{2} \\
& \quad \cdot\left(\lambda_{3}(b, x, s, q, 0)\left|f^{\prime}(x)\right|^{q}\right. \\
& \left.\left.\quad+\lambda_{4}(b, x, s, q, 0)\left|f^{\prime}(b)\right|^{q}\right)^{1 / q}\right\}
\end{aligned}
$$

where $\lambda_{1}, \lambda_{2}, \lambda_{3}$, and $\lambda_{4}$ are defined as in Theorem 4.

Corollary 11. In Theorem 10, additionally, if $\left|f^{\prime}(x)\right| \leq M, x \in$ $[a, b]$, then the inequality

$$
\begin{gathered}
\left|f(x)-\frac{a b}{b-a} \int_{a}^{b} \frac{f(u)}{u^{2}} d u\right| \leq \frac{a b}{b-a} M\left(\frac{1}{1+p}\right)^{1 / p} \\
\cdot\left\{(x-a)^{2}\left(\lambda_{1}(a, x, s, q, 0)+\lambda_{2}(a, x, s, q, 0)\right)^{1 / q}\right. \\
\left.+(b-x)^{2}\left(\lambda_{3}(b, x, s, q, 0)+\lambda_{4}(b, x, s, q, 0)\right)^{1 / q}\right\}
\end{gathered}
$$

holds.

Theorem 12. Let $f: I \subset(0, \infty) \rightarrow \mathbb{R}$ be a differentiable function on $I^{\circ}, a, b \in I^{\circ}$ with $a<b$ and $f^{\prime} \in L[a, b]$. If $\left|f^{\prime}\right|^{q}$ is harmonically s-convex on $[a, b]$ for $q>1,1 / p+1 / q=1$, then, for all $x \in[a, b]$, one has

$$
\begin{aligned}
& \left|f(x)-\frac{a b}{b-a} \int_{a}^{b} \frac{f(u)}{u^{2}} d u\right| \\
& \quad \leq \frac{a b}{b-a}\left\{\left(\lambda_{1}(a, x, 0, p, p)\right)^{1 / p}(x-a)^{2}\right.
\end{aligned}
$$

$$
\begin{aligned}
& \cdot\left(\frac{\left|f^{\prime}(x)\right|^{q}+\left|f^{\prime}(a)\right|^{q}}{s+1}\right)^{1 / q} \\
& +\left(\lambda_{3}(b, x, 0, p, p)\right)^{1 / p}(b-x)^{2} \\
& \left.\cdot\left(\frac{\left|f^{\prime}(x)\right|^{q}+\left|f^{\prime}(b)\right|^{q}}{s+1}\right)^{1 / q}\right\},
\end{aligned}
$$

where $\lambda_{1}$ and $\lambda_{3}$ are defined as in Theorem 4.

Corollary 13. In Theorem 12, additionally, if $\left|f^{\prime}(x)\right| \leq M, x \in$ $[a, b]$, then the inequality

$$
\begin{aligned}
& \left|f(x)-\frac{a b}{b-a} \int_{a}^{b} \frac{f(u)}{u^{2}} d u\right| \leq \frac{a b}{b-a} M\left(\frac{2}{s+1}\right)^{1 / q} \\
& \cdot\left\{\left(\lambda_{1}(a, x, 0, p, p)\right)^{1 / p}(x-a)^{2}\right. \\
& \left.\quad+\left(\lambda_{3}(b, x, 0, p, p)\right)^{1 / p}(b-x)^{2}\right\}
\end{aligned}
$$

holds.

In [7], İşcan introduced the concept of harmonically $(\alpha, m)$-convex functions and established some HermiteHadamard type inequalities for this class of function. This class of functions is defined as follows.

Definition 14. The function $f:(0, \infty) \rightarrow \mathbb{R}$ is said to be harmonically $(\alpha, m)$-convex, where $\alpha \in[0,1]$ and $m \in(0,1]$, if

$$
\begin{aligned}
f\left(\frac{m x y}{m t y+(1-t) x}\right) & =f\left(\left(\frac{t}{x}+\frac{1-t}{m y}\right)^{-1}\right) \\
& \leq t^{\alpha} f(x)+m\left(1-t^{\alpha}\right) f(y)
\end{aligned}
$$

for all $x, y \in(0, \infty)$ and $t \in[0,1]$. If the inequality in (18) is reversed, then $f$ is said to be harmonically $(\alpha, m)$-concave.

In [8], Park considered the class of $(s, m)$-convex functions in second sense. This class of functions is defined as follows.

Definition 15. For some fixed $s \in(0,1]$ and $m \in[0,1]$, a mapping $f: I \subset[0, \infty) \rightarrow \mathbb{R}$ is said to be $(s, m)$-convex in the second sense on $I$ if

$$
f(t x+m(1-t) y) \leq t^{s} f(x)+m(1-t)^{s} f(y)
$$

holds, for all $x, y \in I$ and $t \in[0,1]$.

Now, we introduce the concept of harmonically $(s, m)$ convex functions in second sense, which generalize the notion of harmonically convex and harmonically $s$-convex functions in second sense introduced by İşcan in $[5,6]$, as follows. 
Definition 16. The function $f: I \subset(0, \infty) \rightarrow \mathbb{R}$ is said to be harmonically $(s, m)$-convex in second sense, where $s \in(0,1]$ and $m \in(0,1]$ if

$$
\begin{aligned}
f\left(\frac{m x y}{m t y+(1-t) x}\right) & =f\left(\left(\frac{t}{x}+\frac{1-t}{m y}\right)^{-1}\right) \\
& \leq t^{s} f(x)+m(1-t)^{s} f(y),
\end{aligned}
$$

$\forall x, y \in I$ and $t \in[0,1]$.

Remark 17. Note that, for $s=1$, harmonic $(s, m)$-convexity reduces to harmonic $m$-convexity and for $m=1$ harmonic $(s, m)$-convexity reduces to harmonic $s$-convexity in second sense (see [6]) and for $s, m=1$ harmonic $(s, m)$-convexity reduces to ordinary harmonic convexity (see [5]).

Proposition 18. Let $f:(0, \infty) \rightarrow \mathbb{R}$ be a function:

(a) if $f$ is $(s, m)$-convex function in second sense and nondecreasing, then $f$ is a harmonically $(s, m)$-convex function in second sense.

(b) If $f$ is a harmonically $(s, m)$-convex function in second sense and nonincreasing, then $f$ is $(s, m)$-convex function in second sense.

Remark 19. According to Proposition 18, every nondecreasing $(s, m)$-convex function in second sense is also a harmonically $(s, m)$-convex function in second sense.

Example 20 (see [9]). Let $0<s<1$ and $a, b, c \in \mathbb{R}$; then, function $f:(0, \infty) \rightarrow \mathbb{R}$ defined by

$$
f(x)= \begin{cases}a, & x=0, \\ b x^{2}+c, & x>0,\end{cases}
$$

is a nondecreasing $s$-convex function in second sense for $b \geq$ 0 and $0 \leq c \leq a$. Hence, by Proposition $18, f$ is a harmonically $(s, 1)$-convex function.

Proposition 21. Let $s \in[0,1], m \in(0,1]$, and $f:[a, m b] \subset$ $(0, \infty) \rightarrow \mathbb{R}$ be an increasing function and $g:[a, m b] \rightarrow$ $[a, m b]$ and $g(x)=m a b /(a+m b-x), a<m b$. Then, $f$ is harmonically $(s, m)$-convex in second sense on $[a, m b]$ if and only if fog is $(s, m)$-convex in second sense on $[a, m b]$. holds.

The following result of the Hermite-Hadamard type

Theorem 22. Let $f: I \subset(0, \infty) \rightarrow \mathbb{R}$ be a harmonically $(s, m)$-convex function in second sense with $s \in[0,1]$ and $m \in$ $(0,1]$. If $0<a<b<\infty$ and $f \in L[a, b]$, then one has the following inequality:

$$
\begin{aligned}
& \frac{a b}{b-a} \int_{a}^{b} \frac{f(x)}{x^{2}} d x \\
& \quad \leq \min \left[\frac{f(a)+m f(b / m)}{s+1}, \frac{f(b)+m f(a / m)}{s+1}\right] .
\end{aligned}
$$

Corollary 23. If one takes $m=1$ in Theorem 22, then one gets

$$
\frac{a b}{b-a} \int_{a}^{b} \frac{f(x)}{x^{2}} d x \leq \frac{f(a)+f(b)}{s+1} .
$$

Corollary 24. If one takes $s=1$ in Theorem 22, then one gets

$$
\begin{aligned}
& \frac{a b}{b-a} \int_{a}^{b} \frac{f(x)}{x^{2}} d x \\
& \quad \leq \min \left[\frac{f(a)+m f(b / m)}{2}, \frac{f(b)+m f(a / m)}{2}\right] .
\end{aligned}
$$

In this paper, we obtain similar inequalities (1) for harmonically $(s, m)$-convex functions and establish some new results of Ostrowski type inequalities for harmonically $(s, m)$ convex functions such that results given in [6] by İşcan are obtained for particular value of $m$.

\section{Main Results}

For finding some new inequalities of Ostrowski type for the functions whose derivatives are harmonically $(s, m)$-convex in second sense, we need the following lemma.

Lemma 25. Let $f: I \subset \mathbb{R} /\{0\} \rightarrow \mathbb{R}$ be a differentiable function on $I^{\circ}$ and $a, b \in I$ with $a<b$. If $f^{\prime} \in L[a, b]$, then

$$
\begin{aligned}
& f(x)-\frac{a b}{b-a} \int_{a}^{b} \frac{f(u)}{u^{2}} d u=\frac{a b}{b-a}\left\{(x-a)^{2}\right. \\
& \cdot \int_{0}^{1} \frac{t}{(t a+(1-t) x)^{2}} f^{\prime}\left(\frac{a x}{(t a+(1-t) x)}\right) d t \\
& -(b-x)^{2} \\
& \left.\quad \cdot \int_{0}^{1} \frac{t}{(t b+(1-t) x)^{2}} f^{\prime}\left(\frac{b x}{(t b+(1-t) x)}\right) d t\right\} .
\end{aligned}
$$

Theorem 26. Let $f: I \subset(0, \infty) \rightarrow \mathbb{R}$ be a differentiable function on $I^{\circ}, m a, b \in I^{\circ}$ with $a<b, m \in(0,1]$, and $f^{\prime} \in$ $L[a, b]$. If $\left|f^{\prime}\right|^{q}$ is harmonically $(s, m)$-convex in second sense on $[a, b / m]$ for $q \geq 1$ with $s \in[0,1]$, then

$$
\begin{aligned}
& \left|f(x)-\frac{a b}{b-a} \int_{a}^{b} \frac{f(u)}{u^{2}} d u\right| \leq \frac{a b}{b-a}\left\{(x-a)^{2}\right. \\
& \cdot\left(\lambda_{1}(a, x, s, q, q)\left|f^{\prime}(x)\right|^{q}\right. \\
& \left.+m \lambda_{2}(a, x, s, q, q)\left|f^{\prime}\left(\frac{a}{m}\right)\right|^{q}\right)^{1 / q}+(b-x)^{2} \\
& \cdot\left(\lambda_{3}(b, x, s, q, q)\left|f^{\prime}(x)\right|^{q}\right. \\
& \left.\left.+m \lambda_{4}(b, x, s, q, q)\left|f^{\prime}\left(\frac{b}{m}\right)\right|^{q}\right)^{1 / q}\right\},
\end{aligned}
$$

where $\lambda_{1}, \lambda_{2}, \lambda_{3}, \lambda_{4}$ are defined as in Theorem 4 . 
Proof. From Lemma 25 and using power mean inequality, we have

$$
\begin{aligned}
& \left|f(x)-\frac{a b}{b-a} \int_{a}^{b} \frac{f(u)}{u^{2}} d u\right| \leq \frac{a b}{b-a}\left\{(x-a)^{2}\right. \\
& \cdot \int_{0}^{1} \frac{t}{(t a+(1-t) x)^{2}}\left|f^{\prime}\left(\frac{a x}{t a+(1-t) x}\right)\right| d t+(b \\
& \left.\quad-x)^{2} \int_{0}^{1} \frac{t}{(t b+(1-t) x)^{2}}\left|f^{\prime}\left(\frac{b x}{t b+(1-t) x}\right)\right| d t\right\} \\
& \quad \leq \frac{a b(x-a)^{2}}{b-a}\left(\int_{0}^{1} 1 d t\right)^{1-1 / q}
\end{aligned}
$$

$$
\begin{aligned}
& \cdot\left(\int_{0}^{1} \frac{t^{q}}{(t a+(1-t) x)^{2 q}}\left|f^{\prime}\left(\frac{a x}{t a+(1-t) x}\right)\right|^{q} d t\right)^{1 / q} \\
& +\frac{a b(b-x)^{2}}{b-a}\left(\int_{0}^{1} 1 d t\right) \\
& \cdot\left(\int_{0}^{1} \frac{t^{q}}{(t b+(1-t) x)^{2 q}}\left|f^{\prime}\left(\frac{b x}{t b+(1-t) x}\right)\right|^{q} d t\right)^{1 / q} .
\end{aligned}
$$

Since $\left|f^{\prime}\right|^{q}$ is harmonically $(s, m)$-convex function in second sense, we have

$$
\begin{aligned}
\left|f(x)-\frac{a b}{b-a} \int_{a}^{b} \frac{f(u)}{u^{2}} d u\right| \leq & \frac{a b(x-a)^{2}}{b-a}\left(\int_{0}^{1} \frac{t^{q}\left[t^{s}\left|f^{\prime}(x)\right|^{q}+m(1-t)^{s}\left|f^{\prime}(a / m)\right|^{q}\right]}{(t a+(1-t) x)^{2 q}} d t\right)^{1 / q} \\
& +\frac{a b(b-x)^{2}}{b-a}\left(\int_{0}^{1} \frac{t^{q}\left[t^{s}\left|f^{\prime}(x)\right|^{q}+m(1-t)^{s}\left|f^{\prime}(b / m)\right|^{q}\right]}{(t b+(1-t) x)^{2 q}} d t\right)^{1 / q} .
\end{aligned}
$$

It is easy to check that

$$
\begin{aligned}
& \int_{0}^{1} \frac{t^{q+s}}{(t a+(1-t) x)^{2 q}} d t \\
&= \frac{\beta(q+s+1,1)}{x^{2 q}} \\
& \cdot{ }_{2} F_{1}\left(2 q, q+s+1, q+s+2 ; 1-\frac{a}{x}\right), \\
& \int_{0}^{1} \frac{t^{q+s}}{(t b+(1-t) x)^{2 q}} d t \\
&=\frac{\beta(1, q+s+1)}{b^{2 q}} \cdot{ }_{2} F_{1}\left(2 q, 1, q+s+2 ; 1-\frac{x}{b}\right), \\
& \int_{0}^{1} \frac{t^{q}(1-t)^{s}}{(t a+(1-t) x)^{2 q}} d t \\
&=\frac{\beta(q+1, s+1)}{x^{2 q}} \\
& \int_{0}^{1} \frac{{ }_{2} F_{1}\left(2 q, q+1, q+s+2 ; 1-\frac{a}{x}\right),}{(t b+(1-t) x)^{2 q}} d t \\
&=\frac{t^{q}(1-t)^{s}}{b^{2 q}} \\
& \quad \cdot{ }_{2} F_{1}\left(2 q, s+1, q+s+2 ; 1-\frac{a}{x}\right) .
\end{aligned}
$$

This completes the proof.

Remark 27. If we take $m=1$ in Theorem 26, we get Theorem 4.
Corollary 28. In Theorem 26, additionally, if $\left|f^{\prime}(x)\right| \leq M$, $x \in[a, b / m]$, then inequality

$$
\begin{aligned}
& \left|f(x)-\frac{a b}{b-a} \int_{a}^{b} \frac{f(u)}{u^{2}} d u\right| \leq \frac{a b}{b-a} M\left\{(x-a)^{2}\right. \\
& \quad \cdot\left(\lambda_{1}(a, x, s, q, q)+m \lambda_{2}(a, x, s, q, q)\right)^{1 / q} \\
& \quad+(b-x)^{2} \\
& \left.\cdot\left(\lambda_{3}(b, x, s, q, q)+m \lambda_{4}(b, x, s, q, q)\right)^{1 / q}\right\}
\end{aligned}
$$

holds.

Remark 29. If we take $m=1$ in Corollary 28, we get Corollary 5.

Theorem 30. Let $f: I \subset(0, \infty) \rightarrow \mathbb{R}$ be a differentiable function on $I, m a, b \in I^{\circ}$ with $a<b, m \in(0,1]$, and $f^{\prime} \in$ $L[a, b]$. If $\left|f^{\prime}\right|^{q}$ is harmonically $(s, m)$-convex in second sense on $[a, b / m]$ for $q \geq 1$ with $s \in[0,1]$, then, for all $x \in[a, b]$, one has

$$
\begin{aligned}
& \left|f(x)-\frac{a b}{b-a} \int_{a}^{b} \frac{f(u)}{u^{2}} d u\right| \leq \frac{a b}{b-a}\left(\frac{1}{2}\right)^{1-1 / q}\{(x \\
& -a)^{2}\left(\lambda_{1}(a, x, s, q, 1)\left|f^{\prime}(x)\right|^{q}\right. \\
& \left.+m \lambda_{2}(a, x, s, q, 1)\left|f^{\prime}\left(\frac{a}{m}\right)\right|^{q}\right)^{1 / q}+(b-x)^{2} \\
& \quad\left(\lambda_{3}(b, x, s, q, 1)\left|f^{\prime}(x)\right|^{q}\right. \\
& \left.\left.\quad+m \lambda_{4}(b, x, s, q, 1)\left|f^{\prime}\left(\frac{b}{m}\right)\right|^{q}\right)^{1 / q}\right\}
\end{aligned}
$$

where, $\lambda_{1}, \lambda_{2}, \lambda_{3}$, and $\lambda_{4}$ are defined as in Theorem 4 . 
Proof. From Lemma 25, power mean inequality, and harmonic $(s, m)$-convexity in second sense of $\left|f^{\prime}\right|^{q}$ on $[a, b / m]$, we have

$$
\begin{aligned}
& \left|f(x)-\frac{a b}{b-a} \int_{a}^{b} \frac{f(u)}{u^{2}} d u\right| \leq \frac{a b}{b-a}\left\{(x-a)^{2} \int_{0}^{1} \frac{t}{(t a+(1-t) x)^{2}}\left|f^{\prime}\left(\frac{a x}{t a+(1-t) x}\right)\right| d t\right. \\
& \left.+(b-x)^{2} \int_{0}^{1} \frac{t}{(t b+(1-t) x)^{2}}\left|f^{\prime}\left(\frac{b x}{t b+(1-t) x}\right)\right| d t\right\} \leq \frac{a b(x-a)^{2}}{b-a}\left(\int_{0}^{1} t d t\right)^{1-1 / q} \\
& +\left(\int_{0}^{1} \frac{t}{(t a+(1-t) x)^{2 q}}\left|f^{\prime}\left(\frac{a x}{t a+(1-t) x}\right)\right|^{q} d t\right)^{1 / q}+\frac{a b(b-x)^{2}}{b-a}\left(\int_{0}^{1} t d t\right)^{1-1 / q} \\
& +\left(\int_{0}^{1} \frac{t}{(t b+(1-t) x)^{2 q}}\left|f^{\prime}\left(\frac{b x}{t b+(1-t) x}\right)\right|^{q} d t\right)^{1 / q} \\
& \quad \leq \frac{a b(x-a)^{2}}{b-a}\left(\int_{0}^{1} \frac{t\left[t^{s}\left|f^{\prime}(x)\right|^{q}+m(1-t)^{s}\left|f^{\prime}(a / m)\right|^{q}\right]}{(t a+(1-t) x)^{2 q}} d t\right)^{1 / q} \\
& +\frac{a b(b-x)^{2}}{b-a}\left(\int_{0}^{1} \frac{t\left[t^{s}\left|f^{\prime}(x)\right|^{q}+m(1-t)^{s}\left|f^{\prime}(b / m)\right|^{q}\right]}{(t b+(1-t) x)^{2 q}} d t\right)^{1 / q} \leq \frac{a b}{b-a}\left(\frac{1}{2}\right)^{1-1 / q} \\
& +(b-x)^{2}\left(\lambda_{3}(b, x, s, q, 1)\left|f^{\prime}(x)\right|^{q}+m \lambda_{4}(b, x, s, q, 1)\left|f^{\prime}\left(\frac{b}{m}\right)\right|^{q}\right)^{1 / q} \\
& +\left\{(x-a)^{2}\left(\lambda_{1}(a, x, s, q, 1)\left|f^{\prime}(x)\right|^{q}+m \lambda_{2}(a, x, s, q, 1)\left|f^{\prime}\left(\frac{a}{m}\right)\right|^{q}\right)^{1 / q}\right.
\end{aligned}
$$

This completes the proof.

Remark 31. If we take $m=1$ in Theorem 30, we get Theorem 6 .

Corollary 32. In Theorem 30, additionally, if $\left|f^{\prime}(x)\right| \leq M$, $x \in[a, b / m]$, then inequality

$$
\begin{aligned}
& \left|f(x)-\frac{a b}{b-a} \int_{a}^{b} \frac{f(u)}{u^{2}} d u\right| \leq \frac{a b}{b-a} M\left(\frac{1}{2}\right)^{1-1 / q} \\
& \cdot\left\{(x-a)^{2}\left(\lambda_{1}(a, x, s, q, 1)+m \lambda_{2}(a, x, s, q, 1)\right)^{1 / q}\right. \\
& \quad+(b-x)^{2} \\
& \left.\cdot\left(\lambda_{3}(b, x, s, q, 1)+m \lambda_{4}(b, x, s, q, 1)\right)^{1 / q}\right\}
\end{aligned}
$$

holds.

Remark 33. If we take $m=1$ in Corollary 32, then we get Corollary 7.

Theorem 34. Let $f: I \subset(0, \infty) \rightarrow \mathbb{R}$ be a differentiable function on $I, m a, b \in I^{\circ}$ with $a<b, m \in(0,1]$, and $f^{\prime} \in$ $L[a, b]$. If $\left|f^{\prime}\right|^{q}$ is harmonically $(s, m)$-convex in second sense on $[a, b / m]$ for $q \geq 1$ with $s \in[0,1]$, then, for all $x \in[a, b]$, one has

$$
\begin{aligned}
& \left|f(x)-\frac{a b}{b-a} \int_{a}^{b} \frac{f(u)}{u^{2}} d u\right| \leq \frac{a b}{b-a}\left\{\lambda_{5}^{1-1 / q}(a, x)(x\right. \\
& -a)^{2}\left(\lambda_{1}(a, x, s, 1,1)\left|f^{\prime}(x)\right|^{q}\right. \\
& \left.+m \lambda_{2}(a, x, s, 1,1)\left|f^{\prime}\left(\frac{a}{m}\right)\right|^{q}\right)^{1 / q}+\lambda_{5}^{1-1 / q}(b, x) \\
& \cdot(b-x)^{2}\left(\lambda_{3}(b, x, s, 1,1)\left|f^{\prime}(x)\right|^{q}\right. \\
& \left.\left.+m \lambda_{4}(b, x, s, 1,1)\left|f^{\prime}\left(\frac{b}{m}\right)\right|^{q}\right)^{1 / q}\right\},
\end{aligned}
$$

where

$$
\lambda_{5}(\theta, x)=\frac{1}{\theta-x}\left\{\frac{1}{x-\theta}-\frac{\ln x-\ln a}{x-\theta}\right\}
$$

and $\lambda_{1}, \lambda_{2}, \lambda_{3}$, and $\lambda_{4}$ are defined as in Theorem 4 . 
Proof. From Lemma 25, power mean inequality, and harmonic $(s, m)$-convexity in second sense of $\left|f^{\prime}\right|^{q}$ on $[a, b / m]$, we have

$$
\begin{aligned}
& \left|f(x)-\frac{a b}{b-a} \int_{a}^{b} \frac{f(u)}{u^{2}} d u\right| \leq \frac{a b}{b-a}\left\{(x-a)^{2}\right. \\
& \cdot \int_{0}^{1} \frac{t}{(t a+(1-t) x)^{2}}\left|f^{\prime}\left(\frac{a x}{t a+(1-t) x}\right)\right| d t \\
& +(b-x)^{2} \\
& \left.\cdot \int_{0}^{1} \frac{t}{(t b+(1-t) x)^{2}}\left|f^{\prime}\left(\frac{b x}{t b+(1-t) x}\right)\right| d t\right\} \\
& \leq \frac{a b(x-a)^{2}}{b-a}\left(\int_{0}^{1} \frac{t}{(t a+(1-t) x)^{2}} d t\right)^{1-1 / q} \\
& \cdot\left(\int_{0}^{1} \frac{t}{(t a+(1-t) x)^{2}}\left|f^{\prime}\left(\frac{a x}{t a+(1-t) x}\right)\right|^{q} d t\right)^{1 / q} \\
& +\frac{a b(b-x)^{2}}{b-a}\left(\int_{0}^{1} \frac{t}{(t b+(1-t) x)^{2}} d t\right)^{1-1 / q} \\
& \cdot\left(\int_{0}^{1} \frac{t}{(t b+(1-t) x)^{2}}\left|f^{\prime}\left(\frac{b x}{t b+(1-t) x}\right)\right|^{q} d t\right)^{1 / q} \\
& \leq \frac{a b(x-a)^{2}}{b-a}\left(\int_{0}^{1} \frac{t}{(t a+(1-t) x)^{2}} d t\right)^{1-1 / q} \\
& \cdot\left(\int_{0}^{1} \frac{t\left[t^{s}\left|f^{\prime}(x)\right|^{q}+m(1-t)^{s}\left|f^{\prime}(a / m)\right|^{q}\right]}{(t a+(1-t) x)^{2 q}} d t\right)^{1 / q} \\
& +\frac{a b(b-x)^{2}}{b-a}\left(\int_{0}^{1} \frac{t}{(t b+(1-t) x)^{2}} d t\right)^{1-1 / q} \\
& \cdot\left(\int_{0}^{1} \frac{t\left[t^{s}\left|f^{\prime}(x)\right|^{q}+m(1-t)^{s}\left|f^{\prime}(b / m)\right|^{q}\right]}{(t b+(1-t) x)^{2 q}} d t\right)^{1 / q} .
\end{aligned}
$$

It is easy to check that

$$
\begin{aligned}
& \int_{0}^{1} \frac{t}{(t a+(1-t) x)^{2}} d t=\frac{1}{x-a}\left\{\frac{1}{a}-\frac{\ln x-\ln a}{x-a}\right\} \\
& \int_{0}^{1} \frac{t}{(t b+(1-t) x)^{2}} d t=\frac{1}{b-x}\left\{\frac{\ln x-\ln a}{x-a}-\frac{1}{b}\right\} .
\end{aligned}
$$

Hence, by use of (29), (30), (31), and (32) for $q=1$ and (40) in (39), we get the desired result.

Remark 35. If we take $m=1$ in Theorem 34, we get Theorem 8.

Corollary 36. In Theorem 34, additionally, if $\left|f^{\prime}(x)\right| \leq M$, $x \in[a, b / m]$, then inequality

$$
\begin{aligned}
& \left|f(x)-\frac{a b}{b-a} \int_{a}^{b} \frac{f(u)}{u^{2}} d u\right| \leq \frac{a b}{b-a} M\left\{\lambda_{5}^{1-1 / q}(a, x)\right. \\
& \cdot(x-a)^{2}\left(\lambda_{1}(a, x, s, 1,1)+m \lambda_{2}(a, x, s, 1,1)\right)^{1 / q} \\
& +\lambda_{5}^{1-1 / q}(b, x)(b-x)^{2} \\
& \left.\cdot\left(\lambda_{3}(b, x, s, 1,1)+m \lambda_{4}(b, x, s, 1,1)\right)^{1 / q}\right\}
\end{aligned}
$$

holds.

Remark 37. If we take $m=1$ in Corollary 36, we get Corollary 9.

Theorem 38. Let $f: I \subset(0, \infty) \rightarrow \mathbb{R}$ be a differentiable function on $I^{\circ}, m a, b \in I^{\circ}$ with $a<b, m \in(0,1]$, and $f^{\prime} \in L[a, b]$. If $\left|f^{\prime}\right|^{q}$ is harmonically $(s, m)$-convex in second sense on $[a, b / m]$ for $q>1,1 / p+1 / q=1$, with $s \in[0,1]$, then

$$
\begin{aligned}
& \left|f(x)-\frac{a b}{b-a} \int_{a}^{b} \frac{f(u)}{u^{2}} d u\right| \leq \frac{a b}{b-a}\left(\frac{1}{p+1}\right)^{1 / p}\{(x \\
& -a)^{2}\left(\lambda_{1}(a, x, s, q, 0)\left|f^{\prime}(x)\right|^{q}\right. \\
& \left.+m \lambda_{2}(a, x, s, q, 0)\left|f^{\prime}\left(\frac{a}{m}\right)\right|^{q}\right)^{1 / q}+(b-x)^{2} \\
& \quad \cdot\left(\lambda_{3}(b, x, s, q, 0)\left|f^{\prime}(x)\right|^{q}\right. \\
& \left.\left.+m \lambda_{4}(b, x, s, q, 0)\left|f^{\prime}\left(\frac{b}{m}\right)\right|^{q}\right)^{1 / q}\right\}
\end{aligned}
$$

where, $\lambda_{1}, \lambda_{2}, \lambda_{3}$, and $\lambda_{4}$ are defined as in Theorem 4 .

Proof. From Lemma 25, Hölder's inequality, and harmonic $(s, m)$-convexity of $\left|f^{\prime}\right|^{q}$ on $[a, b / m]$, one has

$$
\begin{aligned}
& \left|f(x)-\frac{a b}{b-a} \int_{a}^{b} \frac{f(u)}{u^{2}} d u\right| \leq \frac{a b(x-a)^{2}}{b-a}\left(\int_{0}^{1} t^{p} d t\right)^{1 / p}\left(\int_{0}^{1} \frac{1}{(t a+(1-t) x)^{2 q}}\left|f^{\prime}\left(\frac{a x}{t a+(1-t) x}\right)\right|^{q} d t\right)^{1 / q} \\
& +\frac{a b(b-x)^{2}}{b-a}\left(\int_{0}^{1} t^{p} d t\right)^{1 / p}\left(\int_{0}^{1} \frac{1}{(t b+(1-t) x)^{2 q}}\left|f^{\prime}\left(\frac{b x}{t b+(1-t) x}\right)\right|^{q} d t\right)^{1 / q} \leq \frac{a b(x-a)^{2}}{b-a}\left(\frac{1}{p+1}\right)^{1 / p}
\end{aligned}
$$




$$
\begin{aligned}
& \left\{\left(\int_{0}^{1} \frac{\left[t^{s}\left|f^{\prime}(x)\right|^{q}+m(1-t)^{s}\left|f^{\prime}(a / m)\right|^{q}\right]}{(t a+(1-t) x)^{2 q}} d t\right)^{1 / q}\right. \\
& \left.+\frac{a b(b-x)^{2}}{b-a}\left(\int_{0}^{1} \frac{\left[t^{s}\left|f^{\prime}(x)\right|^{q}+m(1-t)^{s}\left|f^{\prime}(b / m)\right|^{q}\right]}{(t b+(1-t) x)^{2 q}} d t\right)^{1 / q}\right\} \leq \frac{a b}{b-a}\left(\frac{1}{p+1}\right)^{1 / p} \\
& \cdot\left\{(x-a)^{2}\left(\lambda_{1}(a, x, s, q, 0)\left|f^{\prime}(x)\right|^{q}+m \lambda_{2}(a, x, s, q, 0)\left|f^{\prime}\left(\frac{a}{m}\right)\right|^{q}\right)^{1 / q}\right. \\
& \left.+(b-x)^{2}\left(\lambda_{3}(b, x, s, q, 0)\left|f^{\prime}(x)\right|^{q}+m \lambda_{4}(b, x, s, q, 0)\left|f^{\prime}\left(\frac{b}{m}\right)\right|^{q}\right)^{1 / q}\right\}
\end{aligned}
$$

This completes the proof.

Remark 39. If we take $m=1$ in Theorem 38, we get Theorem 10.

Corollary 40. In Theorem 38, additionally, if $\left|f^{\prime}(x)\right| \leq M$, $x \in[a, b / m]$, then inequality

$$
\begin{aligned}
& \left|f(x)-\frac{a b}{b-a} \int_{a}^{b} \frac{f(u)}{u^{2}} d x\right| \leq \frac{a b}{b-a} M\left(\frac{1}{p+1}\right)^{1 / p} \\
& \cdot\left\{(x-a)^{2}\left(\lambda_{1}(a, x, s, q, 0)+m \lambda_{2}(a, x, s, q, 0)\right)^{1 / q}\right. \\
& \quad+(b-x)^{2} \\
& \left.\cdot\left(\lambda_{3}(b, x, s, q, 0)+m \lambda_{4}(b, x, s, q, 0)\right)^{1 / q}\right\}
\end{aligned}
$$

holds.

Remark 41. If we take $m=1$ in Corollary 40, we get Corollary 11.

Theorem 42. Let $f: I \subset(0, \infty) \rightarrow \mathbb{R}$ be a differentiable function on $I^{\circ}, m a, b \in I^{\circ}$ with $a<b, m \in(0,1]$, and $f^{\prime} \in$ $L[a, b]$. If $\left|f^{\prime}\right|^{q}$ is harmonically $(s, m)$-convex in second sense on $[a, b / m]$ for $q>1,1 / p+1 / q=1$, with $s \in[0,1]$, then one has the following inequality:

$$
\begin{aligned}
\mid f & (x)-\frac{a b}{b-a} \int_{a}^{b} \frac{f(u)}{u^{2}} d u \mid \\
& \leq \frac{a b}{b-a}\left\{\lambda_{1}(a, x, 0, p, p)(x-a)^{2}\right. \\
& \cdot\left(\frac{\left|f^{\prime}(x)\right|^{q}+m\left|f^{\prime}(a / m)\right|^{q}}{s+1}\right)^{1 / q} \\
& +\lambda_{3}(b, x, 0, p, p)(b-x)^{2} \\
& \left.\cdot\left(\frac{\left|f^{\prime}(x)\right|^{q}+m\left|f^{\prime}(b / m)\right|^{q}}{s+1}\right)^{1 / q}\right\}
\end{aligned}
$$

where, $\lambda_{1}$ and $\lambda_{3}$ are defined as in Theorem 4.
Proof. From Lemma 25, Hölder's inequality, and harmonic $(s, m)$-convexity of $\left|f^{\prime}\right|^{q}$ on $[a, b / m]$, we have

$$
\begin{aligned}
\mid f & (x)-\frac{a b}{b-a} \int_{a}^{b} \frac{f(u)}{u^{2}} d u \mid \\
& \leq \frac{a b(x-a)^{2}}{b-a}\left(\int_{0}^{1} \frac{t^{p}}{(t a+(1-t) x)^{2 p}} d t\right)^{1 / p} \\
& \cdot\left(\int_{0}^{1}\left[t^{s}\left|f^{\prime}(x)\right|^{q}+m(1-t)^{s}\left|f^{\prime}\left(\frac{a}{m}\right)\right|^{q}\right]\right)^{1 / q} \\
& +\frac{a b(b-x)^{2}}{b-a}\left(\int_{0}^{1} \frac{t^{p}}{(t b+(1-t) x)^{2 p}} d t\right)^{1 / p} \\
& \cdot\left(\int_{0}^{1}\left[t^{s}\left|f^{\prime}(x)\right|^{q}+m(1-t)^{s}\left|f^{\prime}\left(\frac{b}{m}\right)\right|^{q}\right]\right)^{1 / q} \\
& \leq \frac{a b}{b-a}\left\{\lambda_{1}(a, x, 0, p, p)(x-a)^{2}\right. \\
& \cdot\left(\frac{\left|f^{\prime}(x)\right|^{q}+m\left|f^{\prime}(a / m)\right|^{q}}{s+1}\right)^{1 / q} \\
& +\left.\left(\frac{\lambda_{3}(b, x, 0, p, p)(b-x)^{2}}{s+1}\right)^{\prime}(x)\right|^{q}+m\left|f^{\prime}(b / m)\right|^{q} \\
& \left(\frac{\mid f^{\prime}}{s / q}\right.
\end{aligned}
$$

Remark 43. If we take $m=1$ in Theorem 42, we get Theorem 12.

Corollary 44. In Theorem 42, additionally, if $\left|f^{\prime}(x)\right| \leq M$, $x \in[a, b / m]$, then inequality

$$
\begin{aligned}
& \left|f(x)-\frac{a b}{b-a} \int_{a}^{b} \frac{f(u)}{u^{2}} d u\right| \leq \frac{a b}{b-a} M\left(\frac{2}{s+1}\right)^{1 / q} \\
& \cdot\left\{\left(\lambda_{1}(a, x, 0, p, p)\right)^{1 / p}(x-a)^{2}\right. \\
& \left.\quad+\left(\lambda_{3}(b, x, 0, p, p)\right)^{1 / p}(b-x)^{2}\right\}
\end{aligned}
$$

holds. 
Remark 45. Corollary 44 is exactly as Corollary 13.

\section{Conflict of Interests}

The authors declare that there is no conflict of interests regarding the publication of this paper.

\section{References}

[1] A. Ostrowski, "Über die absolutabweichung einer differentiierbaren funktion von ihrem Integralmittelwert," Commentarii Mathematici Helvetici, vol. 10, no. 1, pp. 226-227, 1938.

[2] Z. Liu, "A note on Ostrowski type inequalities related to some $s$-convex functions in the second sense," Bulletin of the Korean Mathematical Society, vol. 49, no. 4, pp. 775-785, 2012.

[3] M. Alomari, M. Darus, S. S. Dragomir, and P. Cerone, "Ostrowski type inequalities for functions whose derivatives are s-convex in the second sense," Applied Mathematics Letters, vol. 23, no. 9, pp. 1071-1076, 2010.

[4] M. Abramowitz and I. A. Stegun, Eds., Handbook of Mathematical Functions with Formulas, Graphs, and Mathematical Tables, Dover Publications, New York, NY, USA, 1995.

[5] İ. İşcan, "Hermite-Hadamard type inequalities for harmonically convex functions," Hacettepe Journal of Mathematics and Statistics, vol. 43, no. 6, pp. 935-942, 2014.

[6] İ. İşcan, "Ostrowski type inequalities for harmonically s-convex functions," Konuralp Journal of Mathematics, vol. 3, no. 1, pp. 63-74, 2015.

[7] İ. İşcan, "Hermite-Hadamard type inequalities for harmonically $(\alpha, m)$ convex functions," Hacettepe Journal of Mathematics and Statistics, In press.

[8] J. Park, "New Ostrowski-like type inequalities for differentiable $(s ; m)$-convex mappings," International Journal of Pure and Applied Mathematics, vol. 78, no. 8, pp. 1077-1089, 2012.

[9] W. W. Breckner, "Stetigkeitsaussagenfür eine klasse verallgemeinerter konvexer funktonen in topologischen linearen Räumen," Publications de l'Institut Mathématique, vol. 23, pp. 13-20, 1978. 


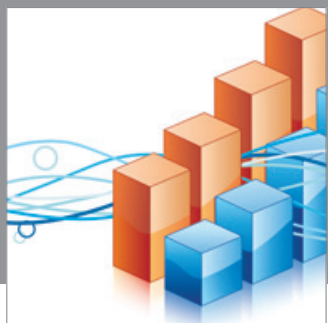

Advances in

Operations Research

mansans

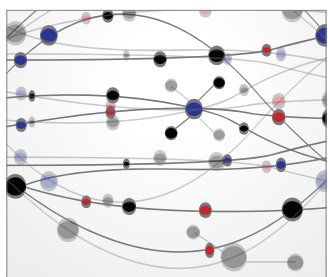

The Scientific World Journal
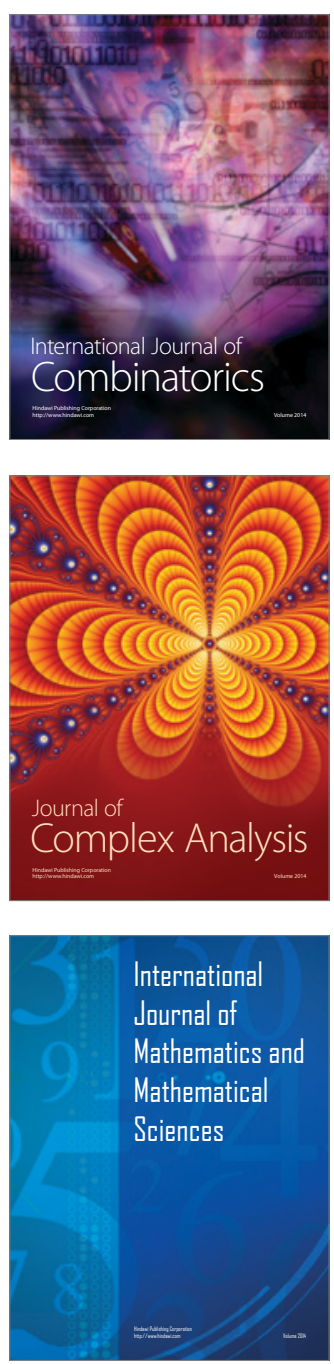
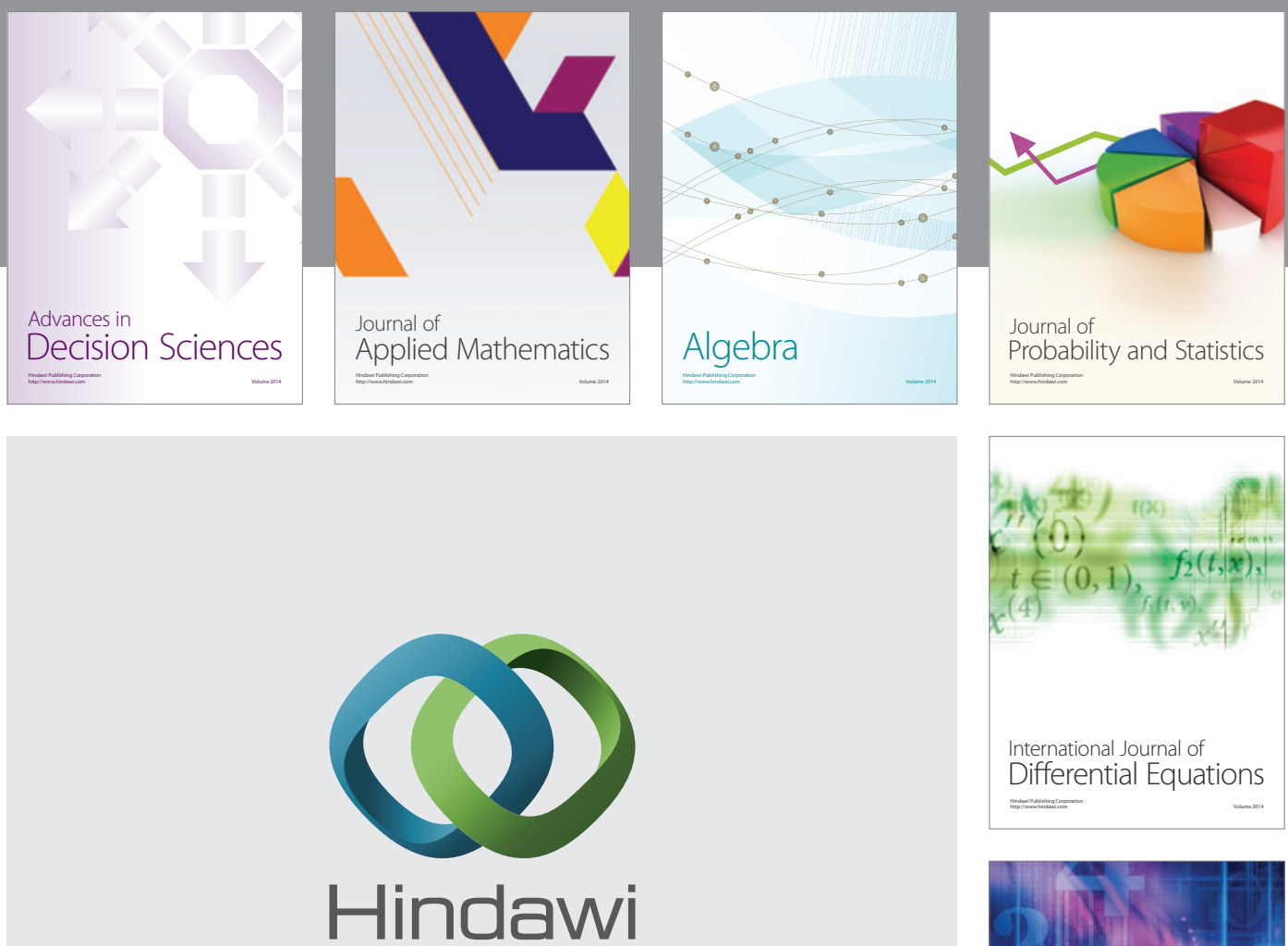

Submit your manuscripts at http://www.hindawi.com
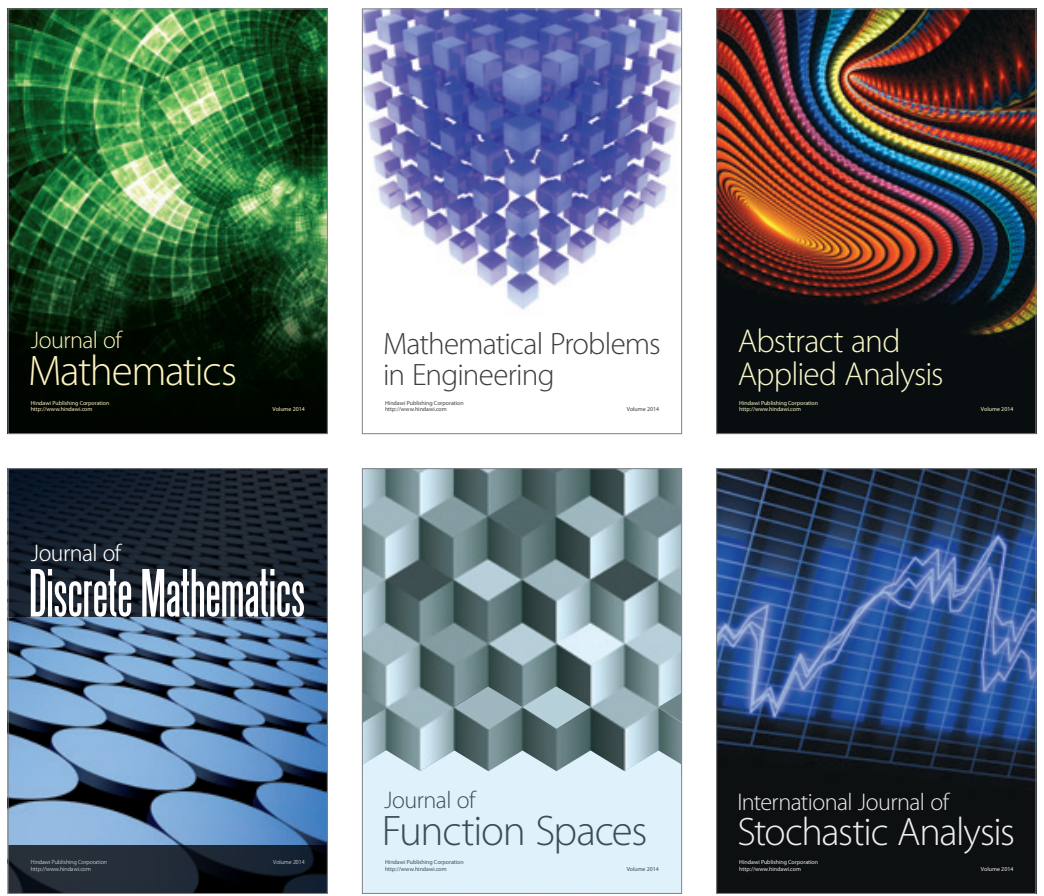

Journal of

Function Spaces

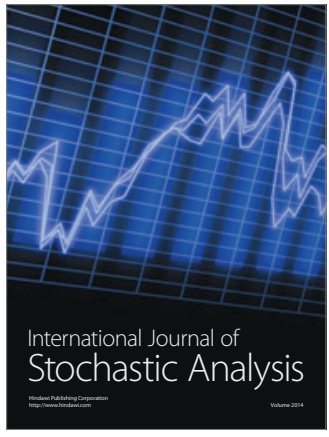

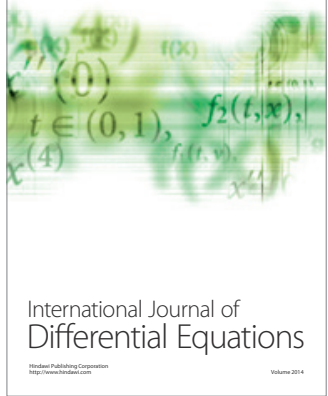
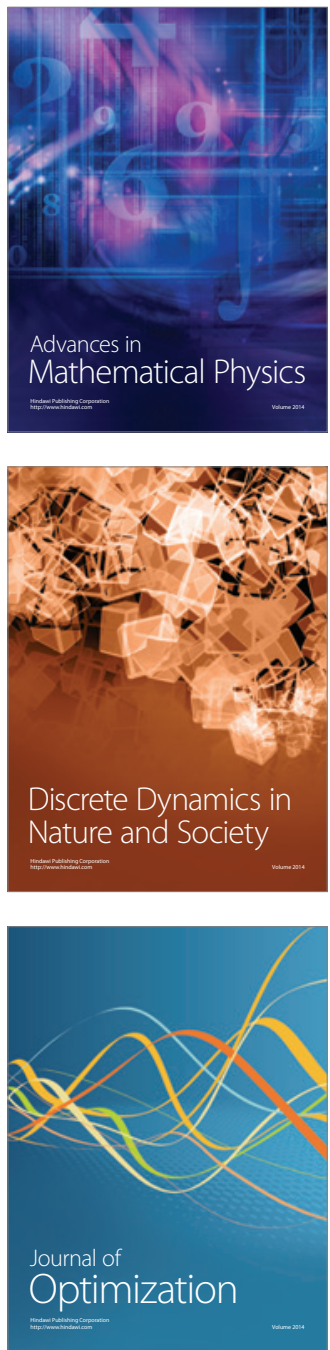